\title{
Moradias do Programa Minha Casa Minha Vida (PMCMV): estudo das localizações em relação às áreas de risco e preservação permanente na cidade de Porto Alegre
}

\author{
Cauana Schumann ${ }^{\mathrm{a}}{ }^{\mathbb{D}}$, Rodrigo de Castilhos da Silva ${ }^{\mathrm{b}}{ }^{\circledR}$, Lívia Teresinha Salomão \\ Piccinini $^{\mathrm{c}}$ (1) e Matheus Gentelini Namiuchi ${ }^{\mathrm{d}}$
}

${ }^{\text {a }}$ Universidade Federal do Rio Grande do Sul, Faculdade de Arquitetura, Programa de Pós-Graduação em Planejamento Urbano e Regional, Porto Alegre, RS, Brasil. E-mail: cauanaschumann@gmail.com

${ }^{\text {b }}$ Universidade Federal do Rio Grande do Sul, Faculdade de Arquitetura, Programa de Pós-Graduação em Planejamento Urbano e Regional, Porto Alegre, RS, Brasil. E-mail: rodrigocasti@ hotmail.com

${ }^{c}$ Universidade Federal do Rio Grande do Sul, Faculdade de Arquitetura, Programa de Pós-Graduação em Planejamento Urbano e Regional, Porto Alegre, RS, Brasil. E-mail: livia.piccinini@ufrgs.br

${ }^{\mathrm{d}}$ Pesquisador independente, Porto Alegre, RS, Brasil. E-mail: matheusnamiuchi@gmail.com

Submetido em 23 de março de 2021. Aceito em 21 de setembro de 2021.

https://doi.org/10.47235/rmu.v9i2.203

\begin{abstract}
Resumo. O governo brasileiro iniciou em 2009 um programa habitacional, o Programa Minha Casa Minha Vida (PMCMV), visando promover o acesso à moradia para a população de baixa renda e classe média baixa no país. $O$ presente artigo avaliou as localizações das moradias do PMCMV, no município de Porto Alegre/RS, na relação com áreas identificadas como de risco e de preservação permanente. A metodologia do estudo está baseada em uma análise documental dos registros junto a órgãos públicos, a partir dos quais foram identificadas e mapeadas as áreas de influência dos empreendimentos que possuem convergência com as áreas de risco e de preservação permanente, sob dois aspectos, constando: (1) apenas dados municipais mapeados; e (2) associando dados municipais e federais. Os resultados apontam que, para a primeira análise 23,43\% das áreas dos empreendimentos do PMCMV encontram-se em áreas de importância ambiental elou de risco da cidade, enquanto na segunda análise, esses valores passam para $56,51 \%$ da área total destes empreendimentos. As conclusões chamam atenção para os impactos destas localizações para a cidade como um todo, quando a administração pública perde a oportunidade de, através da política pública, promover condições mais seguras e sustentáveis para a cidade.
\end{abstract}

Palavras-chave. política habitacional, áreas de risco, áreas de preservação permanente, vulnerabilidade.

\section{Introdução}

O ordenamento territorial da cidade formal depende do planejamento urbano, que envolve fundamentos interdisciplinares, regras, teorias e conhecimentos técnicos específicos, embora, muitas vezes, na prática, seja realizado dentro de um âmbito de conhecimento restrito (Mota, 1981). Segundo Tucci (2007), a organização das ocupações e usos do espaço urbano no Brasil, na sua grande maioria, não considera, por exemplo, as bacias hídricas urbanas e seus afluentes como elementos fundamentais para $o$ desenvolvimento e a vida nas cidades, o que 
tende a promover diversas formas de vulnerabilidade sócio-ambiental.

Por outro lado, a habitação é uma das grandes questões nas cidades brasileiras, particularmente para os mais pobres, cujos domicílios encontram-se em situações precárias, com irregularidades na sua formação e carência de serviços públicos essenciais. O Instituto Brasileiro de Geografia e Estatística aponta que $6 \%$ da população brasileira reside em moradias que apresentam condições inadequadas em sua formação e isto contribui para o desenvolvimento social e econômico destas populações (IBGE, 2018).

As cidades reproduzem de forma paradigmática as injustiças e desigualdades da sociedade e um aspecto disto, no Brasil, diz respeito aos problemas gerados pelas diferenças nas formas de produção e apropriação do ambiente urbano pelos distintos grupos sociais (Rolnik, 2000). A subsistência na cidade depende fundamentalmente do acesso à moradia, à saúde, ao trabalho e à educação, o que constitui um mínimo social, que habilita os indivíduos e os grupos a fazerem suas escolhas e desenvolverem suas atividades e são direitos básicos associados à cidadania como direito constitucional.

No Brasil, o direito à moradia é reconhecido na Emenda Constitucional $n^{\circ} 26 / 2000$, que altera o art. $6^{\circ}$ da Constituição Federal de 1988 , fazendo constar a moradia entre os direitos sociais. $\mathrm{O}$ exercício deste direito, no entanto, tem como pressuposto a

possibilidade de acesso ao solo urbano, que é regulado, juridicamente, pelo direito de propriedade. O solo urbano, por sua vez, é legalmente compreendido como um bem de caráter social, e, tal como a habitação, uma condição básica e indispensável para a qualidade de vida dos habitantes urbanos.

Nos últimos anos, o Estado brasileiro procurou reduzir o déficit habitacional e acelerar a economia por meio da promoção de moradias em larga escala, através do Programa Minha Casa Minha Vida (PMCMV). A iniciativa, no seu aspecto amplo e geral é muito significativa, uma vez que, o programa reduziu efetivamente $o$ déficit habitacional no Brasil em aproximadamente até um quarto do tamanho que seria, caso a política não existisse
(Ministério da Economia, 2020) . Porém, também permite diversos questionamentos quanto às soluções empregadas: desde fatores como a localização dos empreendimentos nas cidades considerando os critérios adotados pelos órgão públicos na locação das moradias em relação ao acesso à infraestrutura, às tipologias dos conjuntos e dos projetos arquitetônicos propostos, e, por conseguinte, os questionamentos estendem-se aos possíveis efeitos das soluções propostas, na vida dos moradores (Gobbato, 2016).

Entende-se que a problemática habitacional não se encerra no número absoluto do déficit de moradias existente ou identificado. A questão passa também pela avaliação das demais condições da habitação associadas a fatores urbanos: as localizações e as condições ambientais ali presentes, particularmente neste momento em que a preocupação com o desenvolvimento urbano sustentável e de práticas que visem minimizar os impactos da ocupação da terra é uma questão que emerge associada aos efeitos sobre as necessidades urbanas e habitacionais e devidas à crise ambiental-ecológica e à pandemia do Covid19. Deste modo, estudos que visem auxiliar o atual quadro urbano representam crescente importância na apreensão e discussão de novas pesquisas, sobretudo, para subsidiar a análise do planejamento urbano e ambiental no ordenamento urbano do território para seu melhor desempenho e desenvolvimento (Salingaros et al., 2006; Salingaros, 2010).

O estado do Rio Grande do Sul, localizado no sul do Brasil, apresenta uma concentração de $13 \%$ da população na sua capital, o município de Porto Alegre (IBGE, 2020). A cidade possui grande influência regional e detém 16,3\% do Produto Interno Bruto (PIB) do estado, apesar disso, o município retrata uma estruturação urbana desigual no seu território e com deficiência no acesso a moradias adequadas (IBGE, 2020; DEMHAB, 2009). Procurando compreender a distribuição habitacional atual, este estudo tem como objetivo descrever e analisar condições locacionais do PMCMV no município de Porto Alegre e identificar a relação da distribuição desses empreendimentos em relação às áreas de risco e às áreas de preservação permanente, apontando possíveis reflexos para os moradores e vulnerabilidades para a cidade. 


\section{Áreas ambientais e áreas de risco}

Os ecossistemas contribuem, direta ou indiretamente, para o bem-estar humano e para o equilíbrio ambiental do Planeta, ao mesmo tempo que a manutenção da quantidade e da qualidade dos recursos naturais determina os serviços de suporte e regulação prestados pelo uso e manejo adequado do solo e a conservação dos recursos hídricos (FAO, 2007). No Brasil, a Lei $\mathrm{N}^{\mathrm{o}} 12.651 / 2012$ estabelece as normas gerais sobre a proteção da vegetação nativa no país, além de determinar quais áreas devem ser destinadas à Preservação Permanente e Reserva Legal no território brasileiro. Estas áreas ambientais, denominadas como Áreas de Preservação Permanente (APPs), são consideradas fundamentais para a preservação dos recursos hídricos, da paisagem, da estabilidade geológica e da biodiversidade, assim facilitando o fluxo gênico de fauna e flora, e fundamentais para proteger o solo e assegurar o bem-estar das populações humanas (Brasil, 2012).

A legislação brasileira determina que a intervenção ou a supressão de vegetação nativa em Área de Preservação Permanente poderá ser autorizada, excepcionalmente, em locais onde a função ecológica esteja comprometida, "para execução de obras habitacionais e de urbanização, inseridas em projetos de regularização fundiária de interesse social, em áreas urbanas consolidadas ocupadas por população de baixa renda" (Brasil, 2012). Desta forma, a expansão urbana de programas habitacionais em áreas ambientais nativas de APPs que não passaram por processo de ocupação ou não estão comprometidas ambientalmente contraria a Lei $\mathrm{N}^{\circ} 12.651 / 2012$. No mesmo sentido, a Lei $\mathrm{N}^{\circ} 12.608 / 2012$ define que as ocupações habitacionais devem ser vedadas em áreas que possam promover risco e desastre às populações no Brasil.

Deve-se entender que a expansão urbana, por si só, altera a cobertura natural do solo, tendendo a provocar efeitos adversos na cidade: a supressão de matas nativas, por exemplo, introduz condutos para o escoamento pluvial alterando os componentes do ciclo hidrológico natural. Quando a alteração do processo hídrico natural acontece de forma desordenada, através, por exemplo, da intervenção em áreas de preservação permanente, o efeito em inundações, enxurradas e enchentes ou movimentos de terra (massa rochosa), ocasiona degradações em áreas de relevância ambiental para as cidades e, as consequências, podem provocar o aumento de desastres ambientais e de áreas de risco no meio urbano (Tucci, 2007).

O crescente número de desastres ambientais decorrentes da ação antrópica, no Brasil e no mundo, nos últimos anos, demonstra as vulnerabilidades em que se encontra grande parte da sociedade e que, em alguns casos, só são conhecidas depois que o evento ocorre. Segundo relatório elaborado pela Escritório das Nações Unidas para a Redução do Risco de Desastres - UNDRR (2020) sobre os riscos de desastres naturais nos últimos 20 anos (2000-2019), houve um aumento de mais de $42 \%$ no número de desastres desta ordem registrados em todo o mundo quando comparado com o período anterior, de 1980 a 1999. As inundações foram responsáveis por mais de $40 \%$ dos desastres, afetando 1,65 bilhão de pessoas, seguidas por tempestades, $28 \%$, terremotos, $8 \%$, e temperaturas extremas, $6 \%$ (UNDRR, 2020).

No Brasil, cerca de 4,3\% da população está exposta em áreas de risco com suscetibilidade a processo erosivos decorrentes de movimentos de massa (deslizamentos de encosta, corridas de massa, solapamentos de margens/terras caídas, queda/rolamento de blocos rochosos e processos erosivos) e/ou decorrentes de processos hidrológicos (inundações, enxurradas, grandes alagamentos) (IBGE, 2018). Os desastres são a concretização dos riscos gerados pelo encontro dos fatores de ameaça e do processo de vulnerabilização que ocorrem, conjugadamente, em um determinado local e em uma determinada escala espacial e temporal (Valencio e Valencio, 2017). Diversos autores apontam que desastres e riscos são construídos socialmente e, muitas vezes, as medidas técnicas de proteção adotadas pelas autoridades constituídas não alcançam a abrangência necessária sobre aquilo que a complexa vida social constrói. A dinâmica profunda das tensões e contradições sociais encontradas nas cidades brasileiras tornam as medidas de monitoramento e de 
diminuição de riscos ineficazes no controle socioambiental (Gonçalves et al., 2012).

No Brasil, um dos critérios adotados para o acesso em programas habitacionais é a priorização de famílias residentes em áreas de risco ou que tenham sido desabrigadas ou que perderam a moradia em razão de enchente, alagamento, transbordamento (Brasil, 2009). Desta forma, o país procura diminuir o número de desastres através do acesso prioritário de populações em áreas vulneráveis no território nacional em programas de moradia.

\section{Programa Minha Casa Minha Vida (PMCMV)}

O Programa Minha Casa Minha Vida (PMCMV) lançado pelo governo brasileiro em 2009 surgiu como medida de combate à crise econômica mundial através de políticas neo-keynesianas de incentivo fiscal à atividade imobiliária como instrumento de crescimento econômico e, paralelamente, como forma de atender às questões habitacionais no país. A sua concepção e implementação estava vinculada ao acesso de moradia para a população baixa renda e classe média baixa (com atendimento familiar na Faixa 1 de 0-3 salários mínimos, na Faixa 2 de 3-6 salários mínimos e na Faixa 3 de 6-10 salários mínimos), mas também aos processos de intensificação da indústria de construção civil como máquina de sustentação e geração de empregos no Brasil (Cardoso e Aragão, 2013).

Em 10 anos de programa, o governo federal construiu mais de 4,4 milhões de unidades habitacionais e está presente em $92 \%$ dos municípios brasileiros (Instituto Escolhas, 2020). Apesar da grande cobertura de atendimento, o PMCMV apresenta problemas quanto à localização de suas unidades, grande parte delas construídas em áreas periféricas e subequipadas da cidade. Esta não é uma característica apenas do PMCMV, mas, sim é um problema identificado nos programas habitacionais que focam no atendimento aos pobres em parte da América Latina (Salingaros et al., 2006; Salingaros, 2010).

Em estudo realizado pelo Instituto Escolhas em parceria com a Fundação Getúlio Vargas (2020), foi identificado que grande parte dos empreendimentos direcionados às camadas de mais baixa renda da sociedade estão localizados distantes e sem infraestrutura de mobilidade, normalmente em regiões periféricas (caracterizadas como áreas de riscos socioeconômicos e ambientais) que não concorrem com novas fronteiras de interesse econômico e expansão imobiliária dos centros urbanos (Gobbato, 2016). A distância das áreas de moradia em relação às áreas centrais das cidades tende a elevar os tempos de deslocamentos dentro da cidade, impactando diretamente na mobilidade urbana, com custos adicionais de várias ordens (passagens, tempo, acesso a serviços e comércio, dentre outros) para estas populações economicamente fragilizadas, além da problemática ambiental (poluição do ar e degradação do solo). Ao analisar as localidades dos empreendimentos do PMCMV na cidade de Porto Alegre, Gobbato (2019) identifica que parte dos espaços criados para a população residente do PMCMV não promove a diminuição da exclusão social no município, pois não fornece acesso às infraestruturas urbanas de saúde, educação, lazer, transporte e trabalho na cidade.

A Lei 11.977/2009, que dispõe sobre o Programa Minha Casa, Minha Vida e a regularização fundiária de assentamentos localizados em áreas urbanas, institui a responsabilidade em determinar as localidades do PMCMV na cidade como compartilhada entre o governo federal e municipal, onde deve-se observar a "localização do terreno na malha urbana ou em área de expansão que atenda aos requisitos estabelecidos pelo Poder Executivo federal, observado o respectivo plano diretor" (Brasil, 2009, Art. $5^{\circ}$ ).

No município de Porto Alegre, a Lei Complementar $n^{\circ}$ 434/1999 dispõe sobre o desenvolvimento da cidade e institui o Plano Diretor de Desenvolvimento Urbano Ambiental (PDDUA) com o princípio do cumprimento das funções sociais da cidade e da propriedade urbana. Com a criação do PMCMV e diante da relevância do tema, o município criou a Comissão de Análise e Aprovação de Demanda Habitacional Prioritária (CAADHAP) através do Decreto ${ }^{\circ}$ 16.477/2009 e a reestruturou conforme o Decreto $N^{\circ} 19.866 / 2017$. Sua principal atribuição é promover a análise, aprovação, licenciamento e carta de habitação dos empreendimentos enquadrados no Programa 
Minha Casa Minha Vida no Município de Porto Alegre de forma célere, garantindo o que está referendado pelo PDDUA e pelo Estatuto da Cidade (Porto Alegre, 2009; Porto Alegre, 2010; Porto Alegre, 2017).

Porém, as relações políticas, econômicas e sociais acabam determinando, muitas vezes, a implantação destes empreendimentos sobre áreas da cidade com infraestrutura, serviços e equipamentos públicos insuficientes e/ou com características urbanas, ambientais e sociais frágeis, impactando diretamente na distribuição espacial do território (Gobbato, 2016), pois é do promotor imobiliário o direito de escolher a área de localização do empreendimento. Esta possibilidade, por si só, não garante, já na proposta do Programa, que áreas servidas por moradias de caráter social (HIS) sejam atendidas plenamente, pois a localização, para ser mais lucrativa, leva as empresas a buscarem glebas localizadas nas franjas das cidades, onde encontram áreas maiores com melhores preços, exatamente devido à insuficiente urbanização (comércio, equipamentos e serviços de saúde, de transporte, etc.) ou infraestruturas (vias e arruamentos, redes de esgoto, abastecimento de água e eletricidade, etc.). Essa possibilidade faz também com que os empreendimentos avancem sobre áreas rurais e naturais do município (e até mesmo de municípios vizinhos) com efeitos devastadores sobre o ambiente natural, a flora e a fauna, afastando as áreas agricultáveis da cidade e apropriando-se de áreas de preservação (matas, riachos, nascentes, banhados) que são ignoradas e suprimidas nos procedimentos para a construção habitacional. Consequentemente, verifica-se que está na própria raiz do PMCMV facilitações e flexibilizações que favorecem o não cumprimento das funções sociais da cidade e da propriedade urbana, na sua plenitude, como a ampliação das faixas de renda para a liberação do incentivo econômico das instituições financeiras.

\section{Ordenamento Territorial e Segregação Espacial}

Assim, identifica-se que a expansão desordenada do território, no país, provoca diversos impactos ambientais e sociais negativos, reproduzindo a exclusão da população mais pobre relativamente às infraestruturas básicas. Rezende (2000), observa que os aspectos socioeconômicos (salários, renda, educação, tamanho da população, estrutura familiar, idade e outros) e a dimensão espacial (grandes distâncias, território diversificado) são importantes para explicar a ausência de infraestrutura urbana, nas cidades brasileiras. Maricato (2015) também contribui nesse sentido, ao identificar que apesar das melhorias nas condições de vida dos trabalhadores em termos salariais e de consumo desde inícios do século XXI, as questões estruturais de moradia, mobilidade e saneamento básico ainda não foram resolvidas no Brasil.

Segundo o Departamento Municipal de Habitação (2009), o processo de ocupação territorial do município de Porto Alegre é marcado pela presença constante de ocupações irregulares. A concentração industrial na capital do estado do Rio Grande do Sul, a partir da década de 40 , provocou uma grande movimentação de migrantes, provenientes do interior do estado, em busca de emprego para a cidade. Porém, os baixos salários, a falta de qualificação profissional e com início da exploração do solo urbano, esta população foi deslocada para áreas periféricas, as denominadas vilas urbanas, que apesar de estarem próximas dos centros urbanos, não possuíam infraestrutura adequada. Ao longo dos anos, houve um aumento de núcleos e vilas de ocupação irregular em Porto Alegre e assim, a cidade passou a reproduziu um sistema excludente, obrigando a população empobrecida a habitar locais com situação de risco geológico e hidrológico para os habitantes (DEMHAB, 2009).

De acordo com Villaça (1998) a segregação é um processo segundo o qual diferentes classes ou camadas sociais tendem a se concentrar em determinada região ou conjunto. $\mathrm{O}$ autor salienta que o alto desnível social entre classes, no Brasil, associado à dimensão das camadas miseráveis geram um padrão espacial que corrobora com a segregação populacional por setores. A segregação espacial ocorre em setores específicos da cidade, onde a estruturação interna urbana obedece, prioritariamente, à lógica de localização das camadas de mais alta renda que procuram ocupar áreas com boa acessibilidade e, assim, determinam a qualidade de infraestrutura em outras áreas da cidade através do descolamento 
progressivo dos serviços de equipamentos urbano na sua direção (Villaça, 1998). Outro fator decisivo desta formação espacial, ainda segundo Villaça (1998), seria o tardio desenvolvimento urbano e industrial do país quando comparado com países europeus, que teve início somente na década de 30.

Harvey (1980), discorrendo sobre a forma como o capitalismo estrutura seus processos globalmente, apresenta os processos sistêmicos do capitalismo na produção do espaço. Para o autor, a desigualdade urbana é vista como uma reprodução do processo capitalista, no qual, as operações destrutivas e reorganizadoras do território agem como mecanismos de integração do seu funcionamento. $\mathrm{O}$ ambiente construído, se transforma na base de investimento da expansão e reorganização geográfica através do capital. Já Santos (2000), sobre a mesma temática, salienta que, em um mundo globalizado, a eficácia das ações está estreitamente relacionada com a sua localização, assim, os atores mais poderosos se reservam os melhores pedaços do território e deixam "o resto" para os outros.

A análise de Abramo (2007) sobre as metrópoles latino-americanas, ressalta a visão do mercado na produção do espaço urbano. As práticas utilizadas pelo mercado, muitas vezes vinculam o território natural, destinados à preservação, para ocupação habitacional de baixa renda, contribuindo para a degradação do meio urbano. E, nesse mesmo sentido, Acselrad (2001) apresenta a relação da desigualdade social e da desigualdade ambiental na formação do meio urbano, como reprodução, local da forma de funcionamento e produção do capitalismo globalmente. Acselrad (2001) destaca que a degradação ambiental tende a acontecer nas comunidades mais pobres como efeito deste funcionamento e produção, que, através do incentivo ao consumo e à geração de resíduos, impõe esta realidade. Os efeitos negativos produzidos pelo sistema global são encaminhados para a parcela mais pobre de cada sociedade e, desta forma, este processo de transferências de cima para baixo, permite a continuidade do padrão tecnológico e locacional, como na sua origem.

\section{Metodologia}

\section{Local de estudo}

A região de estudo é o município de Porto Alegre, capital do estado do Rio Grande do Sul, representada na Figura 1. A escolha do local se deve à sua importância e referência regional. Porto Alegre apresenta uma área territorial de 496,8 $\mathrm{km}^{2}$ e, segundo o Instituto Brasileira de Geografia e Estatística, a cidade conta com uma população estimada de 1.488.252 habitantes (IBGE, 2020). 

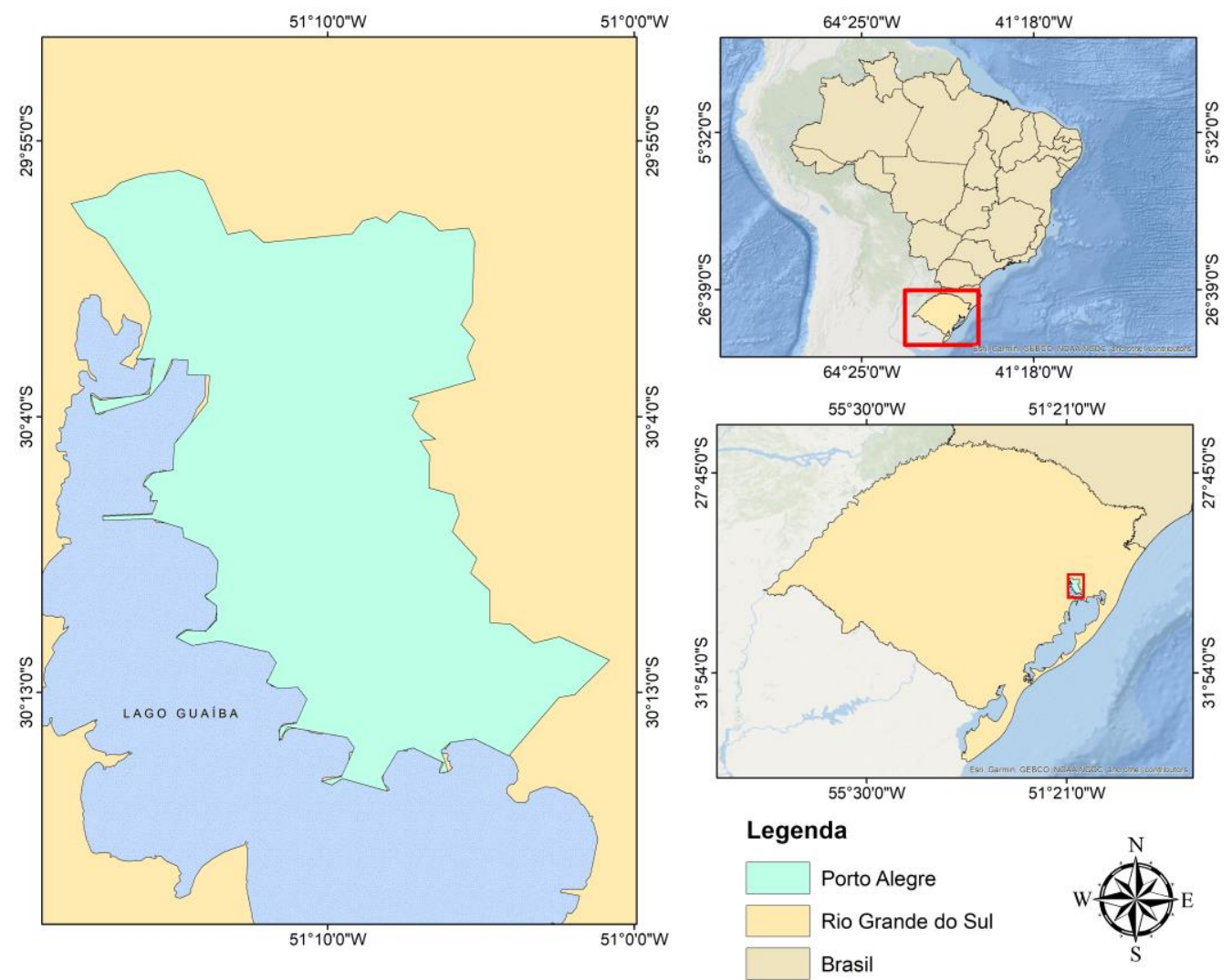

Figura 1. Localização do município de Porto Alegre, capital do estado do Rio Grande do Sul, no Brasil, em verde no mapa à esquerda, circundado nos lados sul e oeste pelo Lago Guaíba.

Fonte: Elaboração dos autores com informações disponíveis pelo IBGE (2010).

\section{Coleta e análise de dados}

O estudo consiste em uma Pesquisa

Documental, Descritiva e Exploratória, relacionada a dados secundários disponíveis pela Prefeitura Municipal de Porto Alegre (2018) e o Repositório Institucional de Geociências do Serviço Geológico do Brasil (2015). Nos quais, foram analisados as seguintes informações:

Dados municipais da Prefeitura Municipal de Porto Alegre (2018):

a) Localização dos empreendimentos do PMCMV na cidade de Porto Alegre;

b) Áreas de Risco: identificadas pelo Departamento Municipal de Habitação (DEMHAB) de Porto Alegre como áreas que apresentam risco geológico decorrentes de movimentos de massa (deslizamentos de encosta, corridas de massa, solapamentos de margens/terras caídas, queda/rolamento de blocos rochosos e processos erosivos); c) Área de Preservação Permanente (APP): identificadas pela Secretaria Municipal do Meio Ambiente da Sustentabilidade (SMAMS) da cidade de Porto Alegre como áreas destinadas à preservação permanente em topos de morros e em recursos hídricos.

Dados federais do Serviço Geológico do Brasil (2015):

d) Áreas de Alta Suscetibilidade a Inundação: identificadas pela Companhia de Pesquisa de Recursos Minerais (CPRM) do Serviço Geológico do Brasil para a cidade de Porto Alegre como áreas de risco hidrológico suscetíveis à inundação.

A análise espacial do presente estudo foi realizada no Software ArcGIS versão 10.7, através do método de intersecção, para a definição da área de influência direta.

Assim, a Área de Influência Direta consiste na relação das localidades dos empreendimentos do PMCMV (a) que também encontram-se nas Áreas de Risco e de Preservação 
Permanente identificadas pelas entidades governamentais $(b, c, d)$. Como há uma diferença nas áreas de riscos identificadas pela Prefeitura municipal (b) e pela Companhia de Pesquisa de Recursos Minerais (d), optou-se por realizar duas análises:

1) Levando em consideração somente os dados municipais $(\mathrm{a}, \mathrm{b}, \mathrm{c})$.

2) Levando em consideração dados municipais e federais (a, b, c, d)

A primeira etapa do estudo analisou a espacialização dos dados previamente obtidos pela Prefeitura Municipal de Porto Alegre (2018) e pelo Serviço Geológico do Brasil (2015), avaliando a dispersão das localidades do PMCMV (a), das Áreas de Risco (b), das Áreas de Preservação Permanente (c) e das Áreas de Alta Suscetibilidade a Inundação (d) no município.

Já na segunda etapa, os dados foram avaliados a partir da Área de Influência Direta que compreende as localidades do PMCMV no município de Porto Alegre em convergência com as áreas de risco e de preservação permanente na cidade, considerando os dados municipais (1) e os dados municipais e federais (2) para análise e assim, identificar a relação da distribuição desses empreendimentos quanto a vulnerabilidade dos moradores.

\section{Estudo de caso}

\section{Análise espacial das localizações}

O município de Porto Alegre apresenta divisões territoriais para a Gestão e Planejamento da cidade em macrozonas e segundo a Prefeitura Municipal de Porto Alegre (2018), estas regiões são definidas em conjuntos de unidades de estruturação urbana com características peculiares quanto a aspecto sócio-econômicos, paisagísticos e ambientais, sendo elas:

- Macrozona 1 - Cidade Radiocêntrica: engloba o território compreendido pelo Centro Histórico e sua extensão, constituindo a área mais estrutura do município;

- Macrozona 2-Corredor de Desenvolvimento: constitui a área estratégica para empreendimentos auto-sustentáveis de polarização metropolitana, com integração de equipamentos urbanos;

- Macrozona 3 - Cidade Xadrez: região que deve ser estimulada para o preenchimento dos vazios urbanos e da potencialização de articulações metropolitanas e novas centralidades;

- Macrozona 4 - Cidade da Transição: área que deve manter suas características residenciais, com densificação controlada e valorização da paisagem;

- Macrozona 5 - Cidade Jardim: caracterizada pela baixa densidade, pelo uso residencial predominantemente unifamiliar e elementos naturais integrados às edificações;

- Macrozona 6 - Eixo Lomba-Restinga: área potencial para ocupação residencial miscigenada, em especial para projetos de habitação de caráter social;

- Macrozona 7 - Restinga: bairro residencial cuja sustentabilidade tem base na implantação de parques;

- Macrozona 8 - Cidade Rururbana: área caracterizada pela predominância de patrimônio natural, propiciando atividades de lazer e turismo com uso residencial primário;

- Macrozona 9-Parque Estadual Delta do Jacuí: compreende as unidades de conservação ambiental estadual.

A localização dos empreendimentos do PMCMV identificados no município de Porto Alegre pela prefeitura, até dezembro de 2017, foi sistematizado na Figura 2. Os empreendimentos compreendem uma área total de $16,35 \mathrm{~km}^{2}$ o que corresponde a $3,29 \%$ de todo o território municipal e 5,34\% do território urbano. Com a presença de 8.008 de unidades e média de 3,90 habitantes por domicílio, a cobertura do PMCMV em Porto Alegre apresenta uma densidade demográfica de 1.910,17 habitantes por $\mathrm{km}^{2}$, valor menor que a municipal de $2.837,53$ habitantes por $\mathrm{km}^{2}$ (IBGE, 2020). 


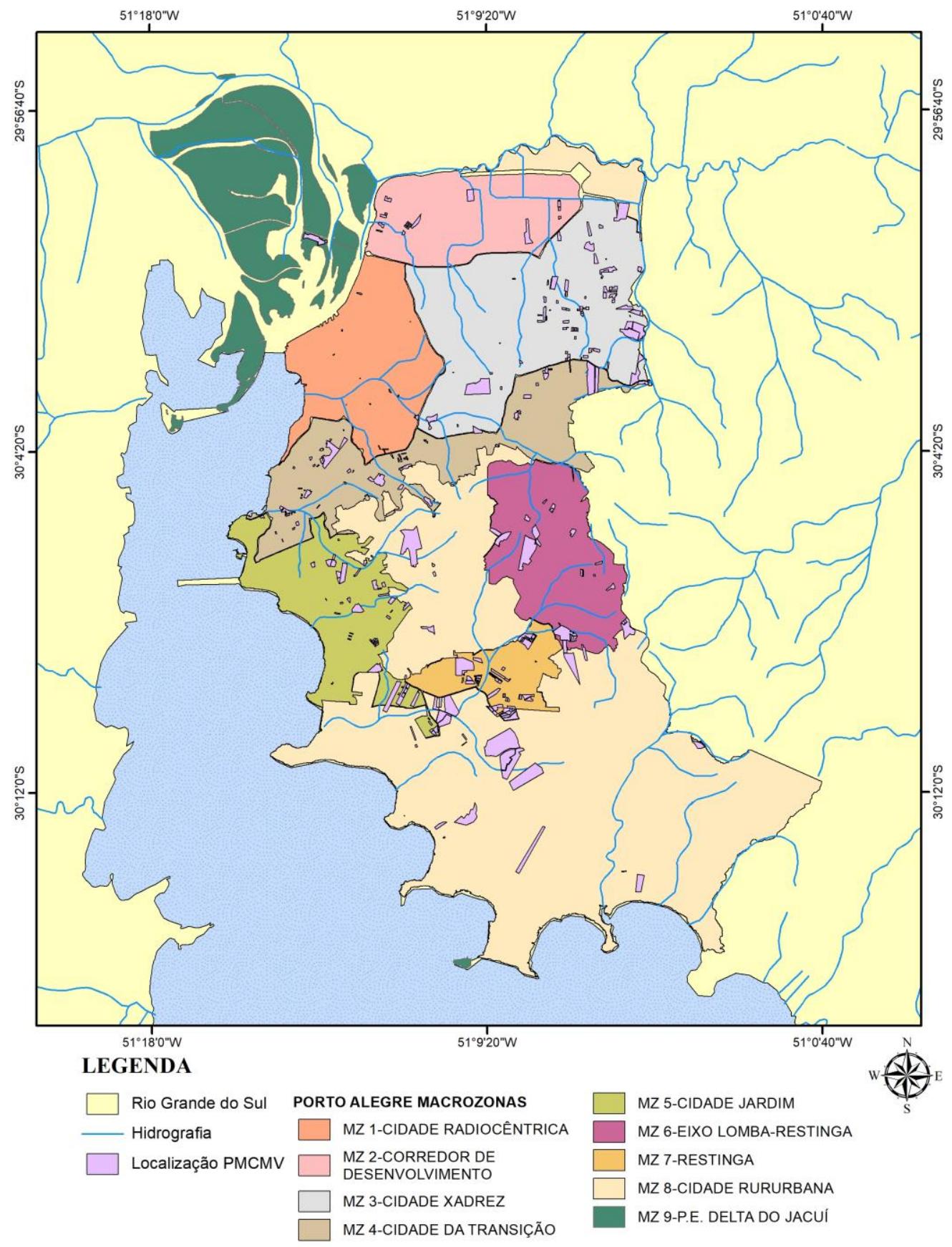

Figura 2. Localização dos empreendimentos do PMCMV no município de Porto Alegre. Fonte: Autores.

A análise espacial demonstra que estes empreendimentos estão presentes em todas as macrozonas de gestão e planejamento da cidade. Ainda, é possível observar que uma das localizações dos empreendimentos do PMCMV está inserida dentro da Macrozona do Parque Estadual Delta do Jacuí, área destinada para a preservação ambiental no município. Além disso, ao analisar as infraestruturas urbanas em Porto Alegre, Gobbato (2016) identifica que apesar dos empreendimentos do PMCMV não se encontrarem desconectados da malha urbana, estão situados majoritariamente nas áreas com menor acesso a infraestrutura no município e estas localizações apresentam inserções urbanas qualitativamente diferentes. 


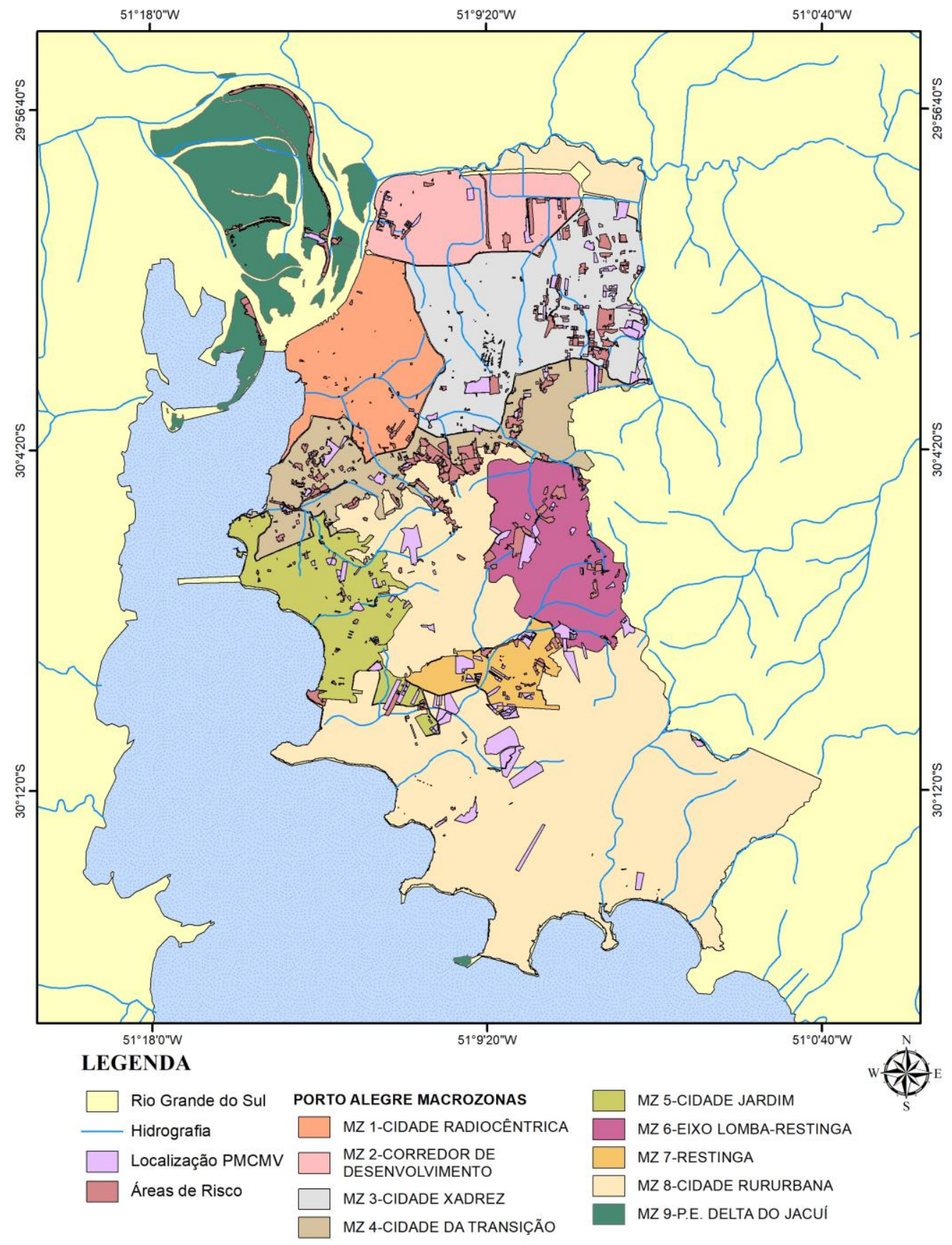

Figura 3. Áreas de Risco no município de Porto Alegre. Fonte: Autores.

Em seguida, na Figura 3, foram sistematizadas as Áreas de Risco (de acordo com o DEMHAB, 2017) do município de Porto Alegre. Estas áreas estão distribuídas em regiões caracterizadas como locais de maior risco à processos erosivos geológicos decorrentes de movimentos de massa (deslizamentos de encosta, corridas de massa, solapamentos de margens/terras caídas, queda/rolamento de blocos rochosos e processos erosivos) na cidade, e somam 18,98 $\mathrm{km}^{2}$, representando $3,82 \%$ da área total da cidade. Ainda, é possível observar que as Áreas de Risco encontram-se em maior concentração nas macrozonas de gestão e planejamento Cidade da Transição e Cidade Xadrez, áreas predominantemente residenciais. 


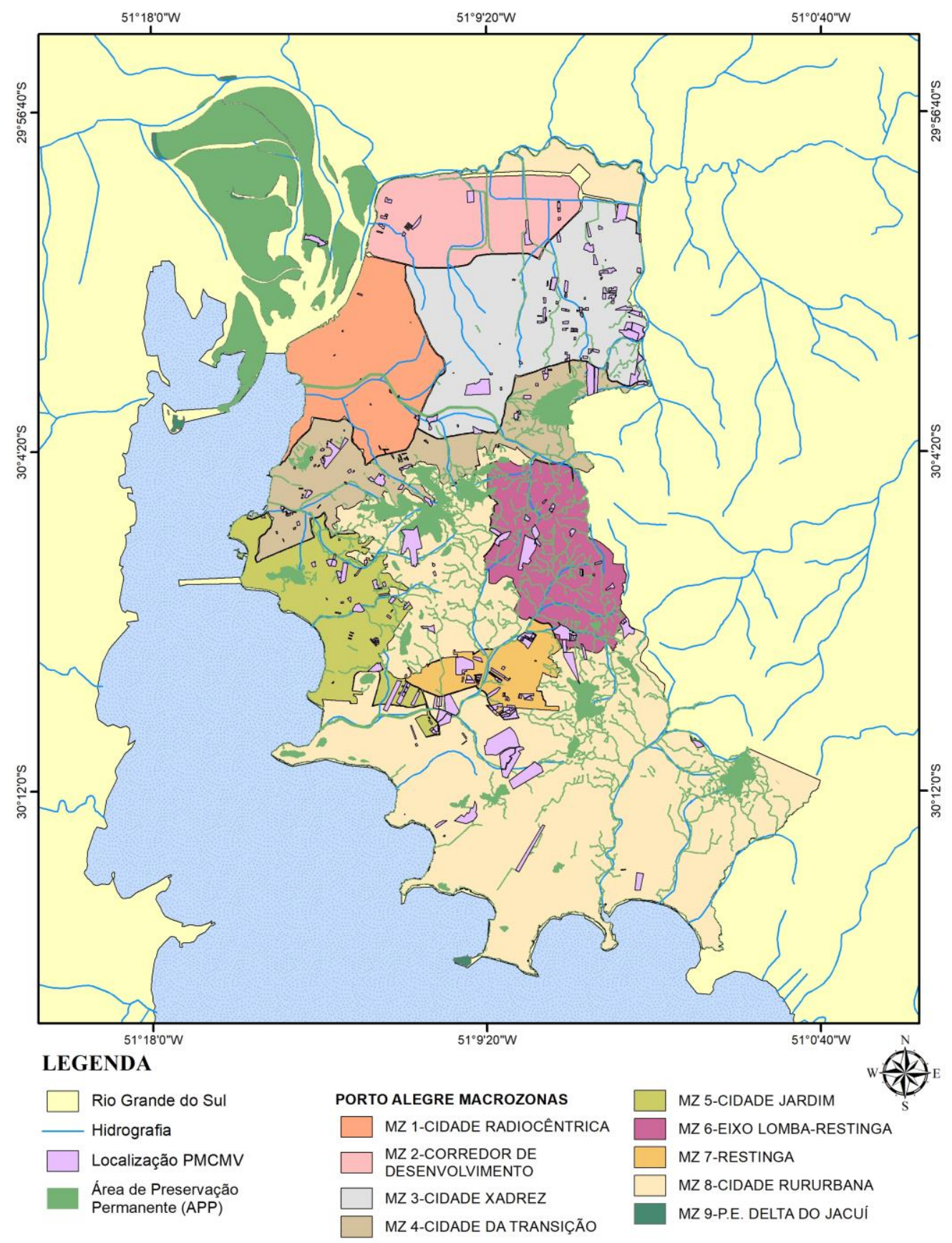

Figura 4. Área de Preservação Permanente (APP) no município de Porto Alegre. Fonte:

Autores.

Já as Áreas de Preservação Permanente (SMAMS, 2017) foram sistematizadas Figura 4. Segundo a Secretaria Municipal, estas áreas são consideradas fundamentais para a preservação dos recursos hídricos na cidade, sobretudo, para a estabilidade geológica e da biodiversidade, presente em $96,8 \mathrm{~km}^{2}$ do território, ou seja, compreendem $19,48 \%$ da área total do município de Porto Alegre. As Áreas de Preservação Permanente estão distribuídas no território municipal com maior concentração na macrozona do Parque Estadual Delta do Jacuí e nas macrozonas Cidade Rururbana e Cidade da Transição. 


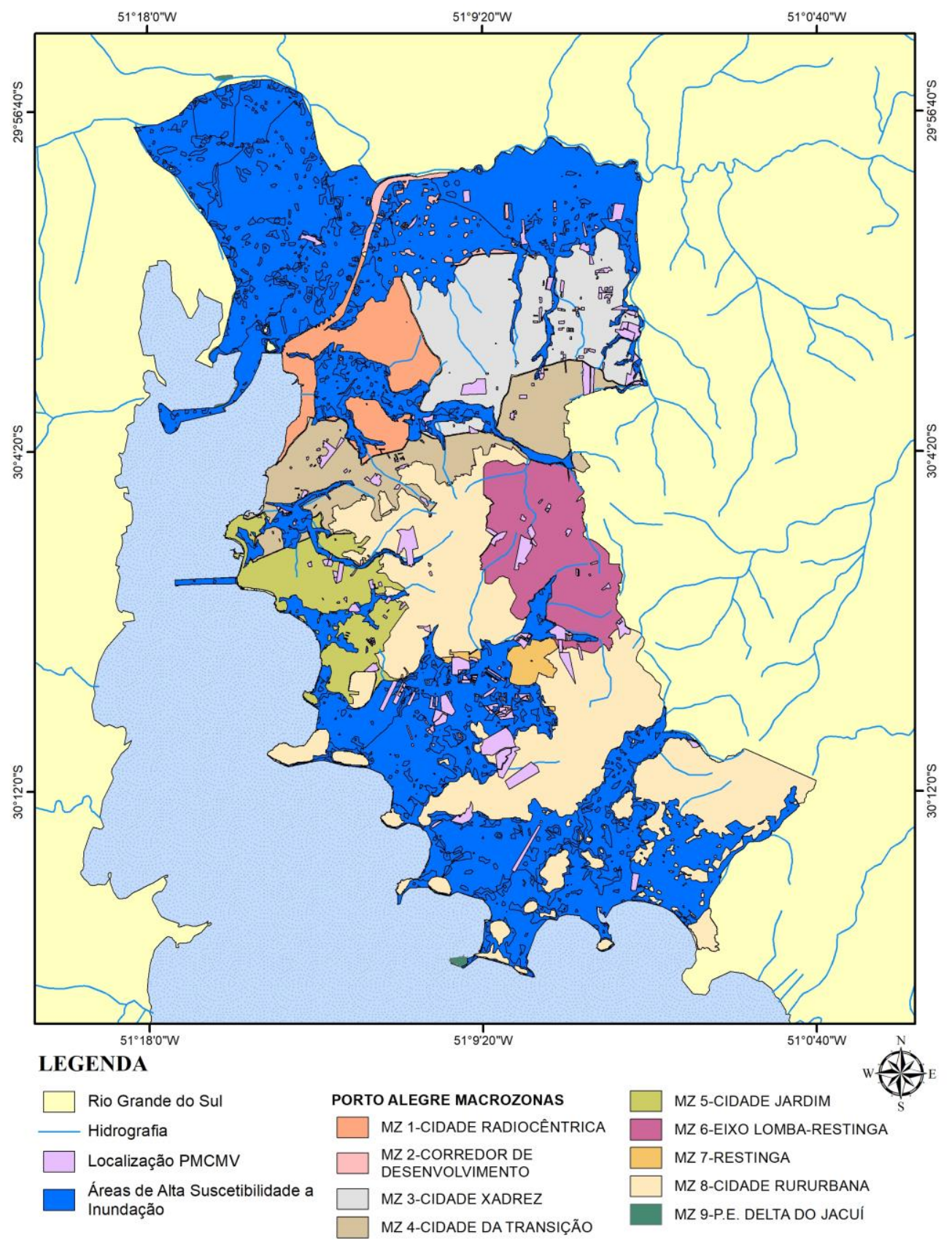

Figura 5. Áreas de Suscetibilidade a Inundação no município Porto Alegre. Fonte: Autores.

E por fim, na Figura 5, estão representadas as Áreas de Suscetibilidade a Inundação identificadas pelo Serviço Geológico do Brasil - CPRM (2015), para o município de Porto Alegre. Estas áreas apresentam alto risco erosivo decorrentes de processos hidrológicos e alcançam grande parte da cidade. Segundo o Serviço Geológico do Brasil - CPRM (2015), Porto Alegre apresenta características geomorfológicas que propiciam movimentos gravitacionais de massa e inundação no seu território, somando uma área total de alta suscetibilidade a movimentos gravitacionais de massa e inundação de $235,39 \mathrm{~km}^{2}$, o que corresponde a 47,38\% do território municipal. As áreas com alta suscetibilidade à inundação estão distribuídas nas regiões de menor cota da cidade, predominantemente, nas macrozonas do Parque Estadual Delta do Jacuí, Corredor de Desenvolvimento, Restinga e Cidade Rururbana. 
Relação das localizações das moradias do PMCMV com as Áreas de Risco e de Preservação Permanente

Com o auxílio do método de intersecção para comparação, foi possível identificar as áreas de influência direta dos empreendimentos do PMCMV que estão em áreas de preservação permanente e/ou de risco na cidade de Porto Alegre. Quando considerado somente os dados municipais, $3,83 \mathrm{~km}^{2}$, ou seja, $23,43 \%$ das áreas dos empreendimentos do PMCMV encontram-se em áreas de vulnerabilidade ambiental e/ou de risco no município, demonstrado na Figura 6.

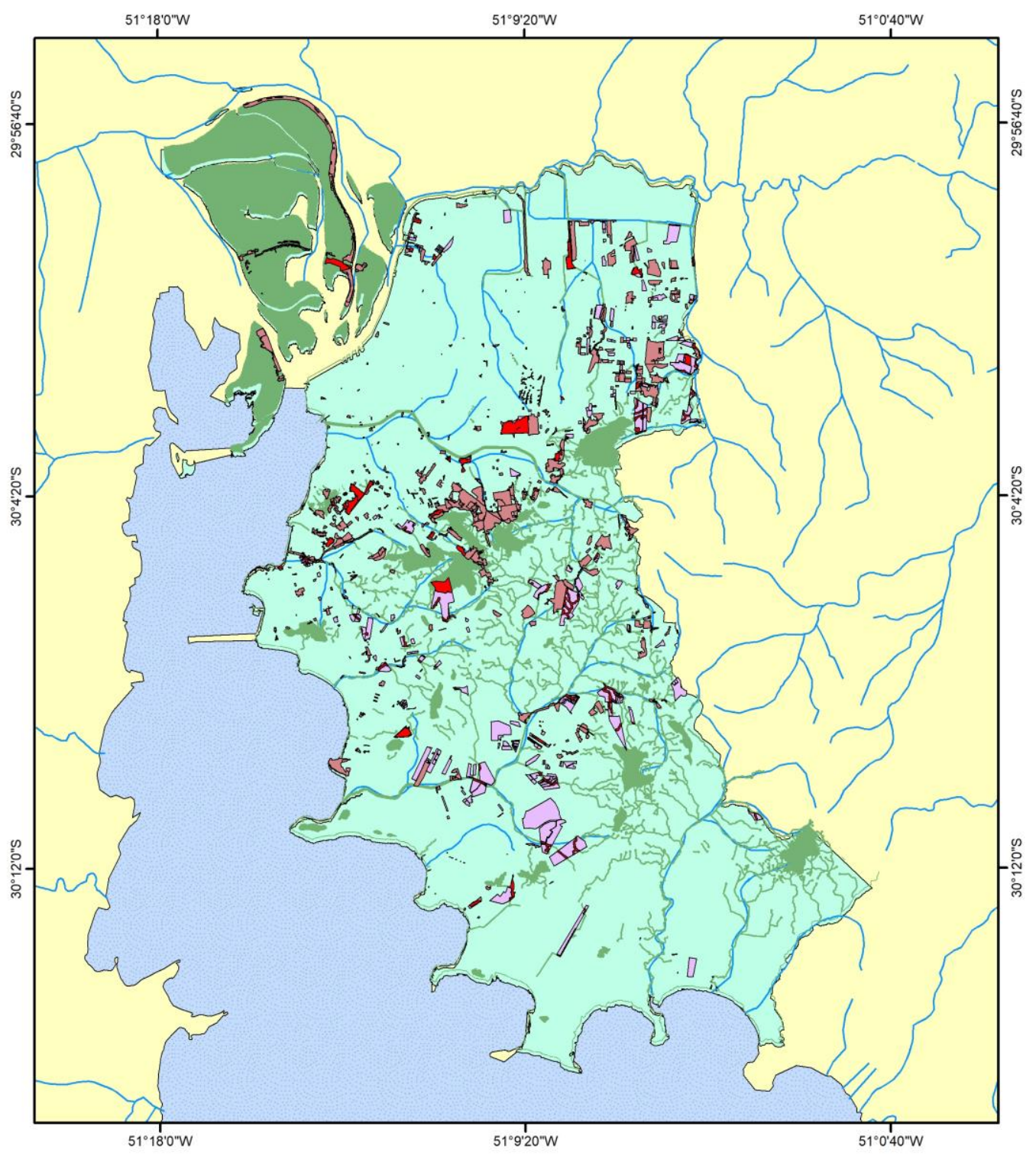

\section{LEGENDA}

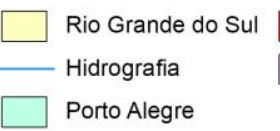

Área de Influência do PMCMV (1) Localização PMCMV

Porto Alegre

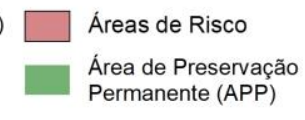

Figura 6. Áreas de Influência do PMCMV ( $1^{\text {a }}$ análise, somente com dados municipais). Fonte: Autores. 
As Áreas de Risco estão presentes em 2,01 $\mathrm{km}^{2}$ da área total do PMCMV, enquanto as APPs alcançam um total de $1,98 \mathrm{~km}^{2}$ dos empreendimentos. Vale ressaltar ainda que, apesar das Áreas de Risco delimitadas pela prefeitura de Porto Alegre compreenderem apenas $3,82 \%$ do território municipal, quando considerada somente as áreas destinadas às moradias do PMCMV no município, as Áreas de Risco atingem 12,29\% da área destes empreendimentos. Assim, concentrando 10,59\% das Áreas de Risco do município nestas localidades.
Em seguida, avaliando além dos dados municipais, os dados disponíveis pelo governo federal referente a áreas de alta suscetibilidade à inundação em Porto Alegre, pode-se observar que ocorre um aumento considerável da área de influência direta. Nesta análise, $9,24 \mathrm{~km}^{2}$ das áreas dos empreendimentos do PMCMV na cidade de Porto Alegre, 56,51\%, encontram-se nas áreas suscetíveis a riscos e/ou a danos ambientais no município, onde $6,66 \mathrm{~km}^{2}$ representam Áreas de Alto Risco a Inundação, como pode ser visualizado na Figura 7.

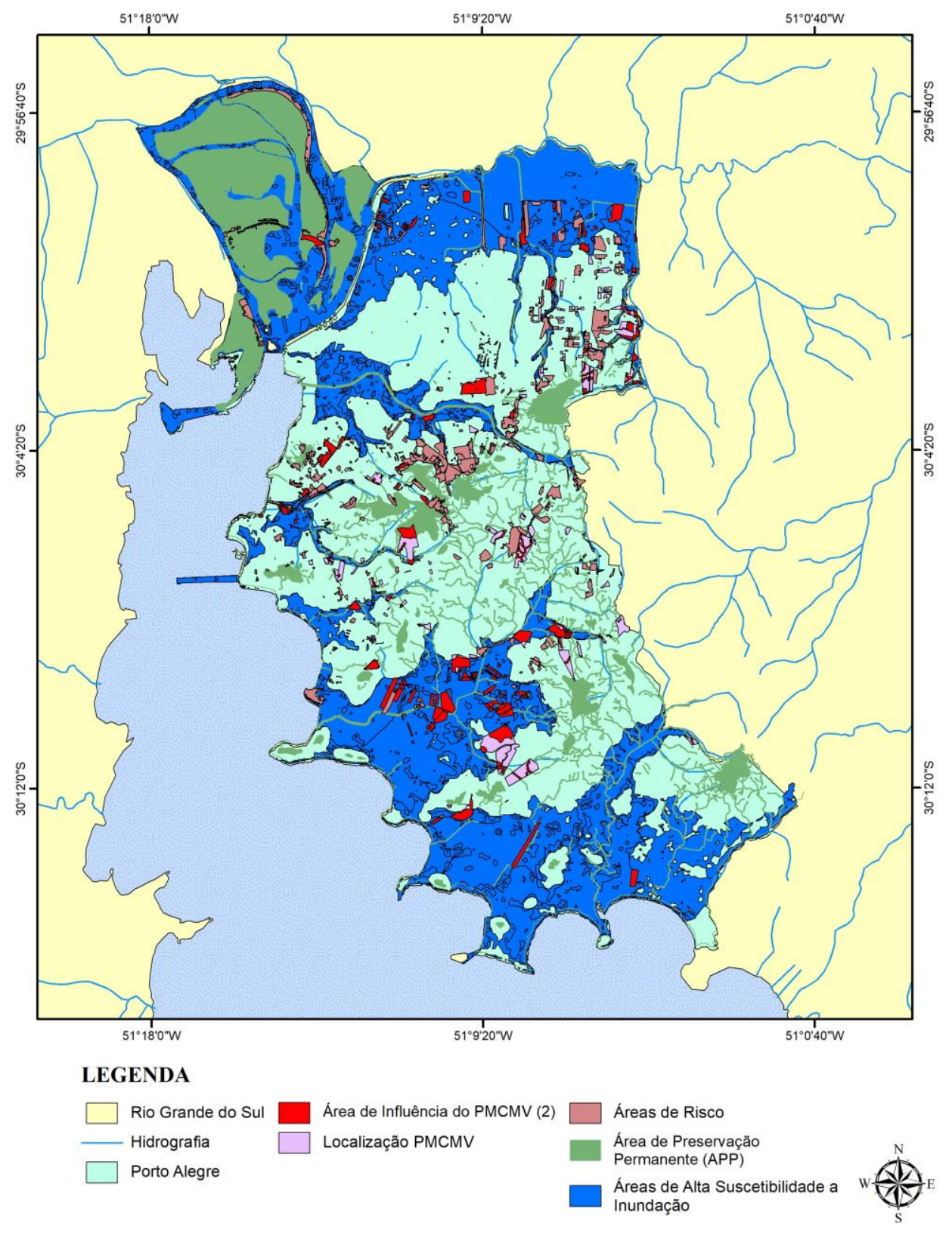

Figura 7. Áreas de Influência do PMCMV ( $2^{\mathrm{a}}$ análise, considerando dados municipais e federais). Fonte: Autores. 
Embora não avaliando a distribuição populacional de residentes diretamente afetada, nestas moradias, a tendência é que o percentual de habitantes atingidos nas localidades analisadas seja proporcional ao de empreendimentos instalados. Ou seja, pode-se afirmar que a proporção da população residente em habitações do PMCMV suscetíveis a riscos de desastres e danos ambientais relativa à população total de residentes em habitação do PMCMV no município de Porto Alegre deve ser de aproximadamente $23 \%$ (quando considerados somente dados municipais) e de $57 \%$ (quando considerados dados municipais e federais).

De acordo com o Instituto Brasileiro de Geografia e Estatística (2018), o município de Porto Alegre possui menos de 1\% de sua população total em Áreas de Risco na cidade. Em contrapartida, o estudo demonstra que $12,29 \%$ da população residente no PMCMV estão em área considerada de risco pela Prefeitura Municipal, isto significa que $35,86 \%$ da população total identificada em Área de Risco pela Prefeitura Municipal está localizada em unidades do PMCMV em Porto Alegre. Entre os municípios que apresentam maior número de habitantes em Áreas de Risco no Brasil, destacam-se o município de Salvador com $45,5 \%$ de sua população, São Paulo com 6\%, e Rio de Janeiro com 7,04\% (Brasil, 2018). Deste modo, os resultados encontrados no estudo podem demonstrar uma maior vulnerabilidade à riscos dos empreendimentos do PMCMV em Porto Alegre, quando comparado com a população em geral na cidade.

Os resultados corroboram para a relação da desigualdade social e da desigualdade ambiental na formação do meio urbano, pois ambientes destinados à preservação acabam destinados para habitações de baixa renda, contribuindo para a problemática associada à crise ambiental, ao incremento da vulnerabilidade e à degradação do meio urbano. Os dados apontam também a probabilidade de degradação ambiental das áreas de preservação permanente no território municipal, exigindo maiores estudos para a real compreensão da dimensão dos impactos sociais e ambientais na cidade. Sobretudo, o estudo realizado pode auxiliar os gestores municipais a identificarem os impactos do processo de organização habitacional a fim de elucidar a problemática dos núcleos habitacionais que encontram-se vulneráveis na cidade e promover uma gestão urbana que vise o desenvolvimento urbano e sustentável.

\section{Conclusões}

Os resultados obtidos no estudo demonstram a vinculação das localizações dos empreendimentos do Programa Minha Casa Minha (PMCMV) com as áreas de risco e as áreas de preservação permanente no município de Porto Alegre. Isto indica, que a distribuição desses empreendimentos na cidade vai influenciar diretamente a qualidade e quantidade dos recursos ambientais, com efeitos ainda não estudados, nem previstos. Além de indicarem alto risco para parte da população residente, chama-se atenção para os possíveis problemas, que ocorrerão no longo prazo e necessitam ser examinados pelo planejamento municipal, no seu papel de prevenir situações de risco.

É possível observar uma convergência entre os resultados do estudo e os trabalhos apresentados na literatura. A pesquisa demonstrou que, quando analisados somente os dados municipais, o percentual das áreas dos empreendimentos do PMCMV que se encontram na área de influência direta a riscos e danos ambientais é de $23,43 \%$. Já, quando considerados os dados municipais e federais, o percentual das áreas dos empreendimentos que se encontram suscetíveis a riscos e danos ambientais aumenta para $56,51 \%$.

As localizações dos empreendimentos do PMCMV, na cidade de Porto Alegre, - em áreas que apresentam importância ambiental e/ou riscos a desastres -, demonstra que, embora o PMCMV tenha, paralelamente à intenção de promover a construção civil, produzido habitações para os pobres urbanos e uma quantidade razoável de moradias foi produzida - o resultado urbano desses empreendimentos tende a manter a exclusão espacial, localizando essa parcela da sociedade nas franjas da cidade. Dessa forma, juntam-se duas debilidades legais: por um lado, a da política nacional, que abriu mão de determinar as localizações, delegando ao município a decisão e, de outro lado, do poder municipal que não tomou decisões sobre as localizações que estavam sob sua responsabilidade legal. 


\section{Referências}

Abramo, P. A. (2007). Cidade Com-Fusa: a mão inoxidável do mercado e a produção da estrutura urbana nas grandes metrópoles latino-americanas. Revista Brasileira de Estudos Urbanos e Regionais, 9(2), 25-54. Disponível em //doi.org/10.22296/2317-1529.2007v9n2p25.

[Consultado em 22 de novembro de 2020]

Acselrad, H. (2001). A duração das cidades: sustentabilidade e risco nas políticas públicas (Coleção espaços do desenvolvimento). Rio de Janeiro, DP\&A/CREA-RJ.

Brasil (1988, 5 de outubro). Constituição da República Federativa do Brasil. Brasília: Diário Oficial da União.

Brasil (2009, 7 de julho). Lei $N^{o}$ 11.977, de 7 de julho de 2009. Dispõe sobre o Programa Minha Casa, Minha Vida - PMCMV e a regularização fundiária de assentamentos localizados em áreas urbanas. Brasília, Diário Oficial da União.

Brasil (2012, 10 de abril). Lei $N^{o} 12.608$, de 10 de abril de 2012. Institui a Política Nacional de Proteção e Defesa Civil. Brasília, Diário Oficial da União.

Brasil (2012, 25 de maio). Lei $N^{o} 12.651$, de 25 de maio de 2012. Dispõe sobre a proteção da vegetação nativa. Brasília, Diário Oficial da União.

Cardoso, A. L. e Aragão, T. A. (2013). Do fim do BNH ao Programa Minha Casa Minha Vida: 25 anos da política habitacional no Brasil. In: Cardoso A. L. O Programa Minha Casa Minha Vida e seus Efeitos Territoriais (1a ed., p.17-65). Rio de Janeiro, Letra Capital.

Departamento Municipal de Habitação DEMHAB (2009). Plano Municipal de Habitação $e$ Interesse Social. Porto Alegre: Prefeitura Municipal de Porto Alegre. Disponível em: lproweb.procempa.com.br/pmpa/prefpoa/demhab/ usu_doc/diagnstico_porto_alegre.pdf. [consultado em 20 de agosto de 2020]

Food and Agriculture Organization of the United Nations - FAO (2004). Payment Schemes for Environmental Services in Watersheds: In: FAO Land and Water Discussion (n.3). Roma, FAO.

Gobbato, F. G. (2016). Justiça Social e Materialidade: O Programa Minha Casa Minha Vida em Porto Alegre. Dissertação de Mestrado. Universidade Federal do Rio Grande do Sul, Porto Alegre.

Gonçalves, J. C. Marchezini, V. e Valencio, N. (2012). Desastres relacionados a colapsos de embalses en Brasil: aspectos sociopolíticos de una seguridad ilusoria. Estudios Sociológicos, (90) 773804.

Harvey, D. (1980). A Justiça Social e a Cidade. São Paulo, Ed. Hucitec.

Instituto Brasileiro de Geografia e Estatística IBGE. (2010). Censo Demográfico - 2010. Rio de Janeiro: IBGE. Disponível em censo2010.ibge.gov.br/resultados.html.

[Consultado em: 18 de dezembro de 2020]

Instituto Brasileiro de Geografia e Estatística IBGE. (2018). População em áreas de risco no Brasil. Rio de Janeiro: IBGE. Disponível em www.ibge.gov.br/apps/populacaoareasderisco/.

[Consultado em 21 de dezembro de 2020]

Instituto Brasileiro de Geografia e Estatística IBGE (2020). Panorama Porto Alegre. Rio de Janeiro: IBGE. Disponível em cidades.ibge.gov.br/brasil/rs/porto-

alegre/panorama [ Consultado em 21 de agosto de 2020]

Instituto Escolha. (2020). Morar Longe: o Programa Minha Casa Minha Vida e a expansão das Regiões Metropolitanas. São Paulo: Projeto em parceria CEPESP/FGV e Instituto Escolhas.

Maricato, E. (2015). Para entender a crise urbana. São Paulo, Editora Expressão Popular.

Ministério da Economia (2020). Relatório de Avaliação: Programa Minha Casa Minha Vida. Brasília: Secretaria Especial da Fazenda - Secretaria de Avaliação, Planejamento, Energia e Loteria. Disponível em //www.gov.br/cgu/ptbr/assuntos/noticias/2021/04/cgu-divulgaprestacao-de-contas-do-presidente-da-republicade-2020/relatorio-de-avaliacao-pmcmv.pdf [Consultado em 20 de agosto de 2020]

Mota, S. (1981). Planejamento urbano $e$ preservação ambiental. Fortaleza, Edições UFC.

United Nations Office for Disaster Risk Reduction - UNDRR (2020). The human cost of disasters: an overview of the last 20 years (2000-2019). Genebra: UNDRR.

Porto Alegre (2009, de 16 de outubro). Decreto $N^{o}$ 16.477 de 16 de outubro de 2009. Dispõe sobre a criação da CAADHAP. Porto Alegre, Diário Oficial de Porto Alegre.

Porto Alegre (2010, de 1 de dezembro). Lei Complementar $N^{o} 434$ de 1 de dezembro de 1999. Dispõe sobre o desenvolvimento urbano no Município de Porto Alegre, institui o Plano Diretor de Desenvolvimento Urbano Ambiental de Porto Alegre e dá outras providências. Porto Alegre, Diário Oficial de Porto Alegre. 
Porto Alegre (2017, de 26 de outubro). Decreto $N^{o}$ 19.866 de 26 de outubro de 2017. Institui e disciplina a Comissão de Análise e Aprovação Demanda Habitacional Prioritária (CAADHAP). Porto Alegre, Diário Oficial de Porto Alegre.

Prefeitura Municipal de Porto Alegre (2018). Plano Diretor de Desenvolvimento Urbano Ambiental. Porto Alegre: Secretaria de Planejamento Municipal.

Rezende, S. C. (2005). Aspectos demográficos da cobertura de serviços de saneamento no Brasil urbano contemporâneo .Tese de Doutorado. Universidade Federal de Minas Gerais, Belo Horizonte.

Rolnik, R. (2000). Regulação Urbanística no Brasil: Conquistas e Desafios de um Modelo em Construção. In Anais do Seminário Internacional: Gestão da Terra Urbana e Habitação de Interesse Social (p.1-19). São Paulo, PUCCAMP.

Salingaros, N. A. (2010). Algorithmic Sustainable Design: Twelve Lectures on Architecture (2a ed.). Portland, Sustasis Press.

Salingaros, N. A. Brain, D. Duany, A. M. Mehaffy, M. W. e Philibert-Petit, E. Introdução por Piccinini,
L. S (2006). Habitação Social na América Latina: uma Metodologia para Utilizar Processos de Autoorganização. In Anais Congresso Ibero-Americano de Habitação Social (p.1-85). Florianópolis, CTHab.

Santos, M. (2000). Por Uma Outra Globalização: Do pensamento único à consciência universal. Rio de Janeiro, Ed. Record.

Serviço Geológico do Brasil - CPRM (2015). Carta de suscetibilidade a movimentos gravitacionais de massa e inundação: município de Porto Alegre $R S$. Brasília: CPRM. Disponível em //rigeo.cprm.gov.br/jspui/handle/doc/15106. [Consultado em: 21 de dezembro de 2020]

Tucci, C. E. M. (2007). Inundações Urbanas. Porto Alegre, ABRH/RHAMA.

Valencio, N. e Valencio, A. (2017). Vulnerability as oppression: the traps of risk-reduction actions. In: V. Marchezini, B. Wisner, L.Londe e S. Saito (orgs), Reduction of Vulnerability to Disasters: from knowledge to action (p.111-137). São Carlos, RiMa Editora.

Villaça, F. (1998). Espaço Intra-urbano no Brasil. São Paulo, Editora Studio Nobel.

\section{Tradução do título, resumo e palavras-chave}

Housing of the Programa Minha Casa Minha Vida (PMCMV): Study of Locations in relation to Risk and Permanent Preservation Areas in the city of Porto Alegre

Abstract. In 2009, the Brazilian government started a housing program, the Programa Minha Casa Minha Vida (PMCMV), aimed at promoting access to housing for the country's low and middle-income population. This article evaluated the locations of the PMCMV homes in the city of Porto Alegre / RS, in relation to at-risk and conservation areas. The methodology of the study is based on a documental analysis of the records from public agencies, in which the areas of influence of the enterprises that converge with the at-risk and conservation areas were identified and mapped, asccording to two aspects: (1) only mapped municipal data; and (2) associating municipal data and national data. The results showed that, for the first analysis, 23.43\% of the PMCMV's project areas are located in areas of environmental importance and / or risk areas in the city, while in the second analysis, these values increased to $56.51 \%$ of the total area of these projects. The conclusions call attention to impacts of these locations on the city as a whole, when the public administration loses opportunity, through public policy, to promote safer and more sustainable conditions for the city.

Keywords: housing policy, risk areas, permanent preservation areas, vulnerability.

Editor responsável pela submissão: Julio Celso Borello Vargas.

Licenciado sob uma licença Creative Commons.

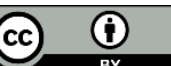

